\title{
DILEMAS DA DIMENSÃO AMBIENTAL NOS ASSENTAMENTOS RURAIS: PERCEPÇÃO E PRÁTICAS AMBIENTAIS
}

\author{
Mario Marcos Lopes ${ }^{1}$ \\ Adriana Maria Risso Caires Silva ${ }^{2}$ \\ Denilson Teixeira ${ }^{3}$ \\ Maria Lúcia Ribeiro ${ }^{4}$
}

Resumo: Esse trabalho tem como proposta geral a análise da percepção e práticas ambientais do assentamento Bela Vista do Chibarro (Araraquara/SP): legislação incidente, uso e ocupação do solo e percepção ambiental do assentado e do corpo técnico. Para a obtenção dos dados utilizou-se pesquisa bibliográfica, documental e imagens de satélite, classificadas e exportadas para um Sistema de Informações Geográficas, além de aplicação questionário semiestruturado com 13 famílias do assentamento e 1 técnico do INCRA em Araraquara. A pesquisa apontou que os assentados possuem a percepção de que o meio ambiente precisa ser preservado para garantir a biodiversidade e sua renovação, mas essa percepção não é oriunda do conhecimento da legislação ambiental: ela é formada da prática da lida diária ou da tradição de práticas conservacionistas.

Palavras-chave: Assentamento de Reforma Agrária; Legislação Ambiental; Percepção Ambiental.

\footnotetext{
${ }^{1}$ Faculdade de Educação São Luís - Jaboticabal/SP, Centro Universitário Barão de Mauá - Ribeirão Preto/SP e Unifesp. E-mail: mmarlopes@ig.com.br.

2 Instituto Municipal de Ensino Superior de Catanduva.

${ }^{3}$ Universidade Federal de Goiás.

${ }^{4}$ Centro Universitário de Araraquara.
} 


\section{Introdução}

Atualmente é possível afirmar que a preocupação com o meio ambiente se faz presente nos diversos segmentos da sociedade, relacionada a diferentes pressões sociais, econômicas e ambientais.

Uma série de eventos, particularmente a partir da década de 1970, de âmbito internacional apresentou ao mundo as consequências negativas do modelo econômico empregado.

Nas décadas seguintes várias tentativas de conter ou amenizar esse processo foram observadas, especialmente com a publicação do relatório Brundtland (1987) - "Nosso futuro comum", que abriu um imenso debate na academia sobre o significado de desenvolvimento sustentável. Em 1992, buscando analisar os avanços e dificuldades referentes à questão ambiental no mundo, ocorreu no Rio de Janeiro, a Conferência sobre o Meio Ambiente e Desenvolvimento das Nações Unidas (Rio 92), na qual, entre outras providências, ficou consagrado o Princípio do Desenvolvimento Sustentável.

Um dos passos importantes para viabilizar essa nova proposta de desenvolvimento implica procedimentos de monitoramento e análise ambiental. Assim será possível, baseado em dados e informações, o acompanhamento dos impactos gerados pelas atividades humanas nos recursos naturais, frente a uma série de diretrizes legais. Dessa forma, as decisões políticas poderão ser embasadas em dados técnicos, contribuindo decisivamente para 0 desenvolvimento sustentável.

No Brasil, historicamente, existe uma concentração de terras, o que resultou na exclusão social e territorial de grande parte da população. Com a redemocratização a luta pela terra ganha representação no contexto nacional e - Estado é pressionado a adotar políticas públicas voltadas ao desenvolvimento socioeconômico da população sem terra, por meio da reestruturação fundiária do país, que visa à adequação dessas políticas de modo a satisfazer as necessidades das populações atendidas pelo projeto de Reforma Agrária (RODRIGUES; SILVA; MOREIRA, 2008).

Em termos legais, foi a Constituição Federal de 1988 que introduziu o conceito da função social da propriedade tornando-se possível a desapropriação com fins de reforma agrária, favorecendo o surgimento dos assentamentos (unidades produtivas de Reforma Agrária).

Embora os assentamentos rurais se tenham destacado como objeto de pesquisa acadêmica a partir dos anos 1990, alguns aspectos de sua constituição e funcionamento têm sido relegados a um plano secundário, apesar das provocações de esferas extra-acadêmicas para que certos debates sejam incorporados. A questão ambiental nos assentamentos rurais é um desses temas, que ainda têm suscitado poucos trabalhos acadêmicos, mas cujo debate já ocupa lugar nas instituições públicas, nos movimentos sociais, 
nas organizações não governamentais com implicações diretas no dia-a-dia das famílias assentadas (FERREIRA NETO; DOULA 2006).

O propósito desta pesquisa é mapear e discutir alguns dilemas da dimensão ambiental nos assentamentos rurais, confrontando o conhecimento da norma legal com a percepção e as práticas ambientais.

Dentro desse contexto, o atual trabalho tem como proposta a análise ambiental do assentamento Bela Vista do Chibarro (Araraquara-SP) sob a dimensão legal (legislação incidente), dimensão espacial (uso e ocupação do solo) e dimensão social (percepção ambiental do assentado e do corpo técnico).

Assim, para obtenção do conjunto de dados e informações relacionado à questão ambiental no assentamento, utilizou-se pesquisa bibliográfica e documental, com destaque para o banco de dados do Núcleo de Pesquisa de Documentação Rural - NUPEDOR. O trabalho de campo foi realizado com 13 famílias e 1 técnico do INCRA (aplicação de questionário semiestruturado). A caracterização do uso e ocupação do solo baseou-se em estudos de imagens de satélite, classificadas e exportadas para um Sistema de Informações Geográficas.

Cabe destacar que a análise ambiental em assentamentos de Reforma Agrária pode se apresentar como um importante mecanismo para simplificar informações e para identificar ações prioritárias capazes de influenciar o comportamento de atores sociais, além de fornecer subsídios para políticas públicas locais.

\section{Procedimentos metodológicos}

O inventário de normas técnicas, com a finalidade de agrupar as principais legislações aplicadas à propriedade rural e aos assentamentos de reforma agrária, foi realizado por meio de pesquisa bibliográfica e documental principalmente na legislação ambiental.

Para obtenção dos dados para análise da percepção ambiental do assentado e do técnico, a pesquisa envolveu um levantamento formal dos dados por meio de pesquisa bibliográfica em documentos científicos oriundos do Instituto de Colonização e Reforma Agrária - INCRA, do Instituto Brasileiro de Geografia e Estatística - IBGE, do Sistema Nacional de Informações sobre Saneamento - SINIS; como da Companhia de Tecnologia de Saneamento Ambiental - CETESB, do Departamento de Água e Energia Elétrica - DAEE e do Departamento Estadual de Proteção dos Recursos Naturais - DEPRN.

Cabe destacar que os resultados referentes às variáveis socioeconômicas foram cedidos pelo NUPEDOR. O Núcleo há mais de 15 anos vem realizando trabalhos técnicos e científicos com diferentes abordagens no assentamento Bela Vista do Chibarro, sendo responsável pelo melhor material 
de caracterização socioeconômica e análise de diferentes processos para o assentamento.

No trabalho de campo (dados primários) foi aplicado um questionário semiestruturado com 13 famílias do assentamento e 1 técnico-coordenador do INCRA em Araraquara em que se buscou levantar dados relativos ao tratamento da água, cuidados em relação ao uso de adubos, tratamento do solo, destino do resíduo sólido, além de verificar o conhecimento sobre a existência de área de Reserva Legal $(R L)$ e Área de Preservação Permanente (APP), assim como, as condições de preservação destas áreas e a fiscalização por parte dos órgãos competentes. O questionário aplicado aos assentados foi baseado na proposta de Alencastro (2007,), cujo pré-teste foi realizado em março de 2011, e a amostragem definitiva realizada em julho de 2011.

Por fim, a caracterização do uso e ocupação do solo baseou-se em estudos de imagens de satélite, classificadas e exportadas para um Sistema de Informações Geográficas.

\section{Inventário de normas técnicas e outras proposições ambientais.}

No inventário de normas técnicas e outras proposições ambientais aplicáveis à propriedade rural e ao assentamento de reforma agrária primeiramente, buscou-se a norma geral aplicável a todas as propriedades rurais para fundamentação da pesquisa, conforme disposta no Quadro 1.

Quadro 1: Resumo da Legislação Federal aplicada à propriedade rural.

\begin{tabular}{|c|c|}
\hline LEGISLAÇÃO & DISPÕE SOBRE: \\
\hline Lei no 12.651/2012 & Dispõe sobre a proteção da vegetação nativa \\
\hline Resolução CONAMA nº 237/97 & Licenciamento Ambiental. \\
\hline Lei $\mathrm{n}^{0} 11.326 / 06$ & Política Nacional da Agricultura Familiar. \\
\hline Lei no 4.504/64 & Estatuto da Terra. \\
\hline Lei no 8.629/93 & $\begin{array}{l}\text { Regulamentação dos dispositivos constitucionais } \\
\text { relativos a reforma agrária. }\end{array}$ \\
\hline Lei $n^{\circ} 6.746 / 79$ & $\begin{array}{l}\text { Altera art. } 49 \text { e } 50 \text {, lei } 4504 / 64 \text { - Estatuto da Terra - } \\
\text { módulos fiscais. }\end{array}$ \\
\hline Lei $n^{0} 7.347 / 85$ & $\begin{array}{l}\text { Ação Civil Pública de responsabilidade por danos } \\
\text { causados ao meio ambiente. }\end{array}$ \\
\hline Lei $n^{0}$ 9.393/96 & Imposto sobre Propriedade Territorial Rural - ITR. \\
\hline Instrução Normativa INCRA nº 50/97 & $\begin{array}{l}\text { Estabelece zonas típicas de módulos ZTM e FMP } \\
\text { (fração mínima parcelamento). }\end{array}$ \\
\hline Lei no 5.868/72 & Cria o Sistema Nacional de Cadastro Rural. \\
\hline
\end{tabular}

Fonte: Silva (2011). 
Todas as normas apresentadas visam à normatização e proteção ambiental nas propriedades rurais, como se pode constatar na Lei ㄲo 4504/64 (Estatuto da Terra) ou na Lei no 7347/85 (Ação Civil Pública), em que é possível responsabilizar por danos causados ao meio ambiente o agressor e exigir dele a reparação do dano ambiental.

Com relação às áreas de $\mathrm{RL}$, como já citado anteriormente, são áreas obrigatórias por força da Lei Federal o 4771/65 (Código Florestal) em qualquer propriedade rural, bem como nos assentamentos de Reforma Agrária.

No Quadro 2 encontra-se um levantamento da legislação federal e estadual paulista, aplicada especialmente a RL.

Quadro 2: Resumo da Legislação aplicada à RL.

\begin{tabular}{|l|l|}
\hline \multicolumn{1}{|c|}{ LEGISLAÇÃO } & \multicolumn{1}{c|}{ DISPÕE SOBRE: } \\
\hline Lei Federal no 10.267/01 & Certificado de Cadastro de Imóvel Rural. \\
\hline Lei Federal no $4.771 / 65$ & Institui o Código Florestal. \\
\hline Lei Federal no $7.803 / 89$ & Definição de área de APP e RL. \\
\hline Decreto Estadual 6.694/08 & Impõe sanções e infrações administrativas. \\
\hline Medida Provisória MP2166-67/01 & Altera o Código Florestal. \\
\hline Lei Estadual no 12.927/08 & Recomposição da RL no Estado de São Paulo. \\
\hline Decreto Estadual 53.939/09 & $\begin{array}{l}\text { Manutenção, recomposição, regeneração natural } \\
\text { compensação da RL no Estado de São Paulo. }\end{array}$ \\
\hline Decreto Estadual 51.006/06 & $\begin{array}{l}\text { Grupo de trabalho, voltado a examinara } \\
\text { recomposição RL. }\end{array}$ \\
\hline Instrução Normativa MMA05/09 & $\begin{array}{l}\text { Procedimentos metodológicos para restauração e } \\
\text { recuperação da APPs e RL. }\end{array}$ \\
\hline Instrução Normativa 04/09 & $\begin{array}{l}\text { Procedimentos teóricos para utilização da RL sob } \\
\text { regime de manejo florestal. }\end{array}$ \\
\hline Lei Federal no 6938/81 & Política Nacional do Meio Ambiente. \\
\hline Lei Estadual no 9989/98 & $\begin{array}{l}\text { Recomposição cobertura vegetal Estado de São } \\
\text { Paulo. }\end{array}$ \\
\hline
\end{tabular}

Fonte: SILVA (2011)

Pode-se notar que a preocupação em instituir, preservar e recompor as áreas de RL está presente nas esferas Estadual e Federal, dado à importância que essas áreas representam ao meio ambiente.

As APPs são igualmente importantes para a manutenção dos biomas, uma vez que, com a sua proteção, melhora significativamente a quantidade e qualidade do fluxo d'água dos rios, córregos e nascentes.

No Quadro 3 encontra-se a legislação pertinente à de APP. 
Quadro 3: Resumo da Legislação aplicada à APP.

\begin{tabular}{|l|l|}
\hline \multicolumn{1}{|c|}{ LEGISLAÇÃO } & \multicolumn{1}{c|}{ DISPÕE SOBRE: } \\
\hline Lei Federal no 7803/89 & Definição de área de APP e RL. \\
\hline Lei Federal no 4771/65 & Institui o Código Florestal. \\
\hline Resolução CONAMA no 303/02 & Parâmetros e definições e limites de APPs. \\
\hline Resolução CONAMA no 302/02 & $\begin{array}{l}\text { Parâmetros e definições e limites APPs de } \\
\text { reservatório artificial e regime uso entorno. }\end{array}$ \\
\hline Instrução Normativa IBAMA 76/05 & Cria a taxa de fiscalização ambiental - TFA. \\
\hline Medida provisória MP2166-67/01 & Altera o Código Florestal. \\
\hline Lei Estadual no 9989/98 & $\begin{array}{l}\text { Recomposição cobertura vegetal Estado de São } \\
\text { Paulo. }\end{array}$ \\
\hline Decreto Estadual no 49566/08 & Intervenção de baixo impacto ambiental em APPs. \\
\hline Resolução CONAMA no 369/06 & $\begin{array}{l}\text { Casos excepcionais de utilidade pública, interesse } \\
\text { social em APP. }\end{array}$ \\
\hline Lei Federal no 6938/81 & Política Nacional do Meio Ambiente. \\
\hline \multicolumn{1}{|c|}{ Fonte: Silva (2011). }
\end{tabular}

As APPs devem ser conservadas e, se possível, mantidas intactas, porém, existe a possibilidade de serem exploradas conforme expresso na Resolução CONAMA nํ 369/06, em casos excepcionais de utilidade pública ou interesse social a sua utilização.

Portanto, é possível a exploração dessas áreas, desde que fundada em utilidade pública ou interesse social e respeitadas as imposições legais.

Dentre todas estas normas deve-se destacar que as principais legislações aplicadas e utilizadas de forma conjunta nos assentamentos de Reforma Agrária são: a Lei 6938/81, a Lei 4771/65 e a Resolução CONAMA 237/1997.

Dentre todas estas normas deve-se destacar que as principais legislações aplicadas e utilizadas de forma conjunta nos assentamentos de Reforma Agrária são: a Lei 6938/81, a Lei 4771/65 e a Resolução CONAMA 237/1997. A Política Nacional do Meio Ambiente (Lei no 6938/81) tem por objetivo a preservação, melhoria e recuperação da qualidade ambiental propícia à vida, visando assegurar, no País, condições ao desenvolvimento socioeconômico, aos interesses da segurança nacional e à proteção da dignidade da vida humana, já o Código Florestal Lei 4.771/65 revogado pela Lei 12.651/2012 estabelece normas gerais sobre a proteção da vegetação, áreas de Preservação Permanente e as áreas de Reserva Legal, tendo como objetivo o desenvolvimento sustentável.

Para a instalação do assentamento são necessários vários estudos prévios, inclusive tem-se a necessidade de realizar o licenciamento ambiental 
previsto na Resolução CONAMA 237/1997, na qual se caracteriza como instrumento de gestão ambiental, instituído pela Política Nacional do Meio Ambiente; tendo a necessidade de se incorporar ao sistema de licenciamento ambiental os instrumentos de gestão ambiental, visando o desenvolvimento sustentável e a melhoria contínua.

Por ocasião do licenciamento ambiental deverão ser analisados inclusive questões relacionadas com os impactos ambientais.

No assentamento Bela Vista do Chibarro por se tratar de antiga fazenda transformada em assentamento as questões ambientais previstas no Código Florestal, na Política Nacional do Meio Ambiente e na Resolução CONAMA 237/97, não se constituíram em obstáculo para sua implantação, o que ocorre atualmente são as questões ambientais oriundas pelo uso e ocupação de áreas de preservação ambiental APP e da RL.

A maioria dos projetos de assentamento de reforma agrária existentes no país foi implantada antes da regulamentação das diretrizes gerais para o licenciamento ambiental dessas atividades. Nesses casos, a legislação vigente desobriga o INCRA, considerado como empreendedor, ao requerimento da Licença Prévia (LP) e Licença de Instalação (LI) e, portanto, da apresentação de documentos como Estudos de Impacto Ambiental (EIA) e Relatório de Impacto de Meio Ambiente (RIMA), apesar de serem exigidos estudos específicos para fins de Licença de Operação Corretiva - LOC (TRINDADE; SCHAEFER; MUNIZ, 2006).

\section{Área de estudo: caracterização socioeconômica e ambiental.}

A área de estudo da presente pesquisa é o Assentamento de Reforma Agrária Bela Vista do Chibarro, localizado na porção sul do município de Araraquara, tendo como principal via de acesso a estrada vicinal ARA-050 que interliga Araraquara a Guarapiranga (distrito do município de Ribeirão Bonito). Por volta do quilômetro 11 da estrada ARA-050, é possível acessar uma estrada de terra até a agrovila do assentamento. O Assentamento está localizado na UGRHI -13 (Bacia Tietê-Jacaré) e abrangue duas sub-bacias, sendo elas a sub-bacia do rio Chibarro e a sub-bacia do rio Jacaré-Guaçu.

O assentamento surgiu como fazenda cafeeira (Bela Vista), transformado em núcleo fabril (seção Bela Vista) de uma usina de açúcar e álcool (Usina Tamoio). Na década de 70, a Usina entrou em processo de falência e em julho de 1980, fez um empréstimo junto à Caixa Econômica Estadual sendo posteriormente comprada pelo Grupo Corona. Durante esse período, devido ao desemprego e às péssimas condições de vida dos trabalhadores empregados na cana, o Sindicato dos Trabalhadores Rurais de Araraquara começa a empreender e lutar pela terra. $O$ processo de desapropriação foi iniciado em 1989, e a criação do assentamento (início da implantação), propriamente dita, foi em 1991. 
Segundo informações técnicas obtidas durante a aplicação do questionário, o assentamento possui uma área total de 3.427 hectares; no período de 1991 a 2006, foi divido em 176 lotes, com média de 15 a 16 hectares cada; a partir de 2007, com o programa de recuperação do assentamento e adesão voluntária de famílias, ocorreu o redimensionamento e a criação de mais 44 lotes, totalizando 220 lotes do assentamento, sendo que existem módulos de 15 a 16 hectares e módulos de 7,5 a 8 hectares, criados a partir da divisão de aproximadamente 44 lotes com módulo original de 16 hectares.

No tocante às características ambientais, o assentamento Bela Vista possui predominantemente regiões com pouca declividade (na faixa de 1 a $8 \%$ ), algumas áreas com declividade mediana (de 8 a 20\%) e locais específicos com declividades mais elevadas (maiores que 20\%). Esse tipo de caracterização é de grande utilidade para fins de planejamento agrícola e ambiental.

Em relação à Geologia, ocupa predominantemente uma região com formação Serra Geral (Basalto) e trechos com formação Botucatu (Arenitos finos a médios), onde há predominância de Latossolo Vermelho-Escuro de dois tipos, e trechos com solos do tipo Litólicos.

O assentamento Bela Vista está localizado em um território ocupado em grande parte por áreas agrícolas, conforme observado por imagens de satélite, com exceção da agrovila, que é ocupada de forma significativa por vegetação.

\section{Resultados e Discussões}

Os resultados foram analisados e discutidos sob a ótica de três dimensões, conforme objetivo deste trabalho são elas: dimensão legal (legislação incidente), dimensão espacial (uso e ocupação do solo) e dimensão social (percepção ambiental do assentado e do corpo técnico).

As primeiras observações levantadas, nesta pesquisa, são referentes à caracterização familiar, observando a renda, gênero de titularidade, tipo de atividade exercida interna ou externamente ao lote, e a escolaridade do assentado detentor do lote.

Observou-se que o gênero preponderante no assentamento quanto à titularidade do lote é essencialmente masculino (11/84,6\%), sendo uma pequena parte $(2 / 15,4 \%)$ destinado às mulheres prevalecendo o gênero masculino na distribuição dos mesmos.

Por meio do banco de dados do NUPEDOR foi possível identificar a idade dos assentados, salientando que, para facilitar a visualização, os resultados foram agrupados por intervalos de idade: entre 40 a 50 anos, de 51 a 60 anos, de 61 a 70 anos, e mais de 70 anos (Figura1). 


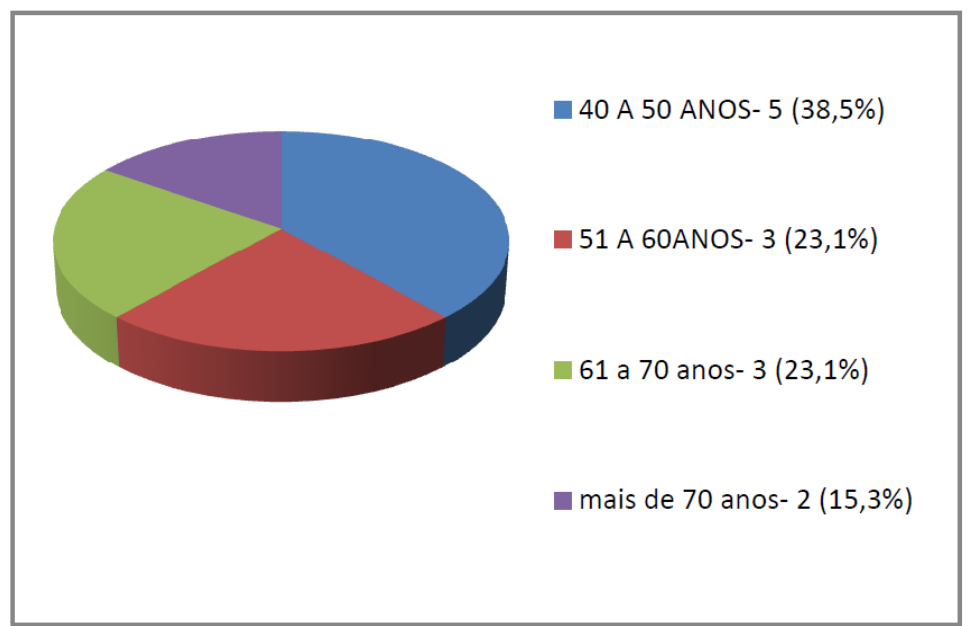

Figura 1: Grupos por idade dos 13 entrevistados. Fonte: Silva (2011).

Observa-se por meio da Figura 1, uma diversificação da faixa etária dos assentados, e levando-se em conta a data de instalação do Assentamento, nota-se que a grande maioria está no local desde a sua implantação.

Por sua vez, a representação do grau de escolaridade dos "chefes de família" dos lotes pode ser visualizada na Figura 2.

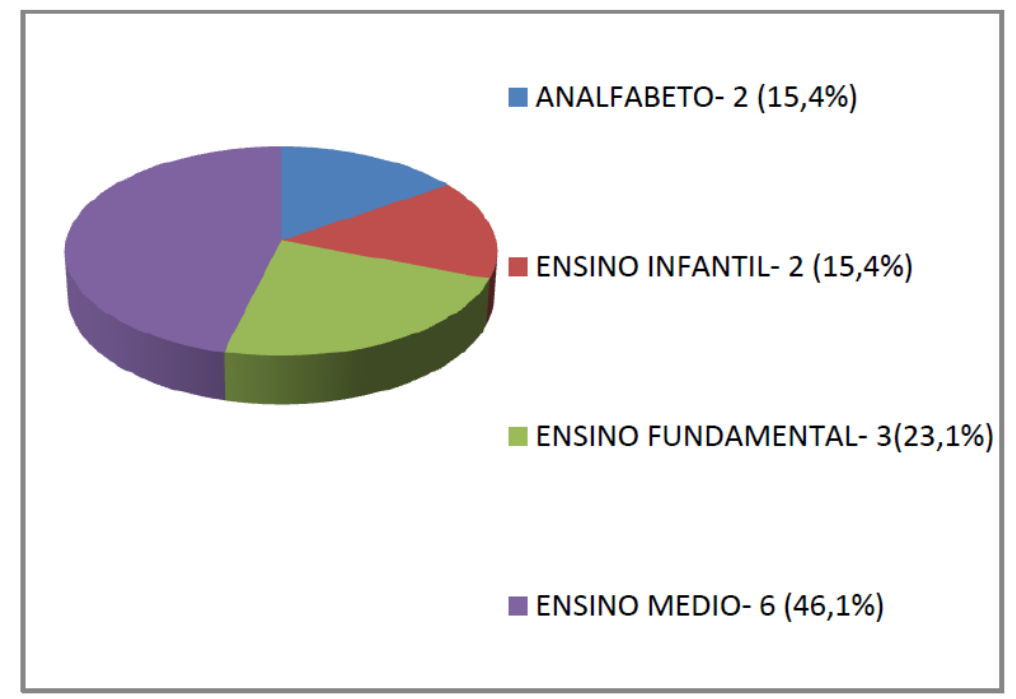

Figura 2: Grau de escolaridade do "chefe da família". Fonte: Silva (2011).

Foi possível identificar, por meio das respostas dos assentados no trabalho de campo, que o grau de escolaridade dos assentados não influencia na obediência ou manutenção das áreas de RL ou APPs.

Revbea, São Paulo, V 10, N²: 301-317, 2015. 
Dentre a maioria dos assentados que não concluíram seus estudos estão os mais velhos, alguns deles analfabetos (com idades entre 68 e 74 anos), já entre os mais novos observa-se a conclusão do ensino médio, salvo uma exceção, cujo assentado do grupo de 51 a 60 anos possui apenas 0 ensino infantil. Cabe destacar que o assentamento conta com uma unidade de escola rural, modelo para toda a região pela excelência na qualidade de ensino e de suas instalações.

Em relação, à renda dos assentados, nota-se que a mesma está intimamente ligada à atividade exercida. Os titulares em sua maioria trabalham apenas nos lotes, e apresentam uma renda entre 1 a 1,5 salário mínimo. Os assentados que apresentam uma renda maior que 1,5 salário mínimo, somam a sua renda pensões ou salários recebidos por outro membro da família, oriundos de atividade exercida fora do assentamento, sendo esta atividade agrícola ou não.

Tomando por base a dimensão ambiental, observa-se que a água é sem dúvida uma das preocupações presentes no assentamento. Com os dados levantados na pesquisa de campo, foi possível identificar a origem da água utilizada nas residências (Figura 3).

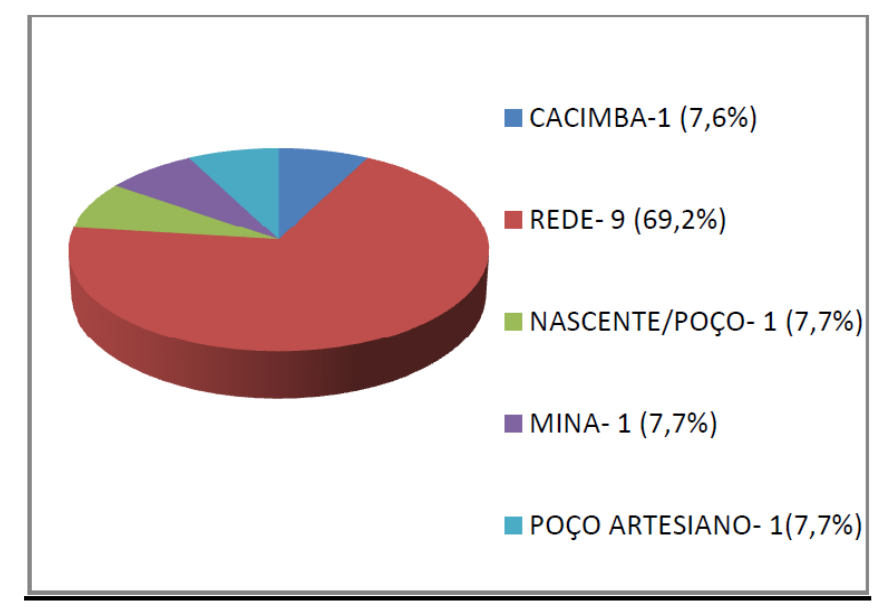

Figura 3: Origem da água para consumo nas residências. Fonte: Silva (2011)

A maioria dos assentados possui abastecimento de água fornecido pelo DAEE em suas residências, em função de residirem na agrovila, onde a água, além de ser proveniente de rede, já chega clorada. As demais famílias que residem nos lotes utilizam a fervura antes do consumo da água.

Em relação à origem da água utilizada na agricultura (Figura 4), algumas famílias assentadas dependem exclusivamente da água da chuva para sua lavoura, (aproximadamente 31\%); porém, a maior parte utiliza a água de mina, poços e córregos nas propriedades. 


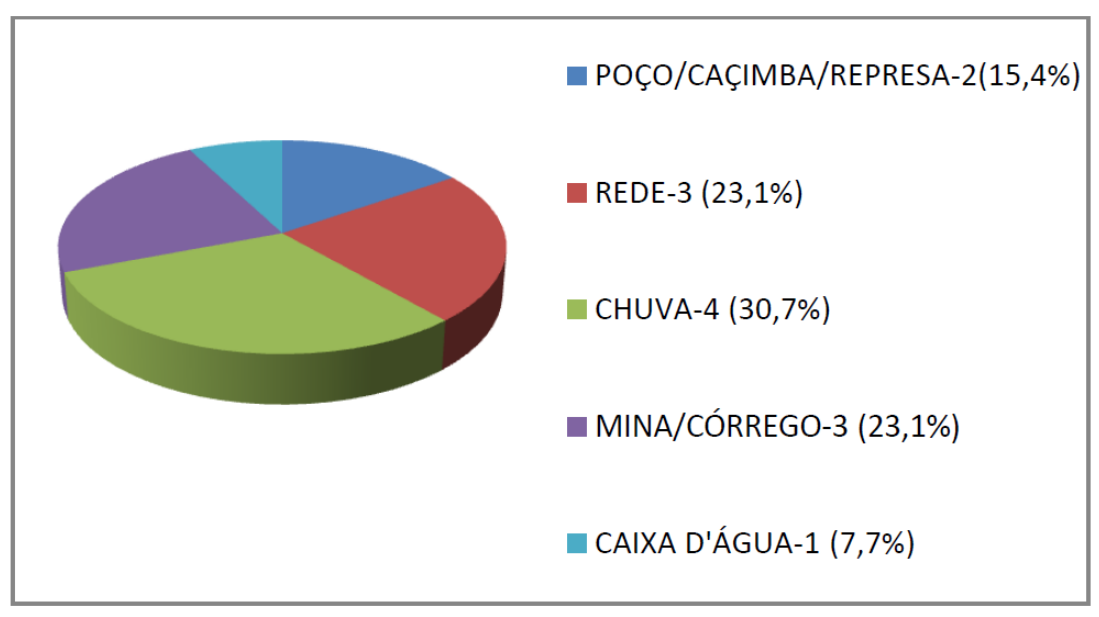

Figura 4: Origem da água para agricultura. Fonte: Silva (2011).

As informações obtidas por meio do questionário aplicado ao Técnico apontam que as principais culturas do assentamento Bela Vista hoje são: canade-açúcar (situação em regularização), 1.500 hectares de milho, sendo que parte dessa plantação (700 hectares) são cultivados para venda adicional da palha para indústria de cigarro; pastagem para gado leiteiro e de corte (pouco significativo em quantidade de cabeças, mas áreas de pasto são significativas 200 hectares); pomares de manga e maracujá, áreas com hortaliças e pimenta, venda concentrada para programa de merenda escolar (+ ou - 50 hectares); e por fim eucalipto que vem substituindo áreas de cana, com média de 150 hectares.

O destino dos efluentes sanitários no assentamento, são a fossa simples e a rede de esgoto. É importante desatacar que os assentados que residem na agrovila possuem rede de esgoto. O destino do esgoto recolhido na agrovila é uma estação de tratamento subterrânea, onde os dejetos humanos depois de tratados são lançados no córrego Jacaré-Guaçú, já os assentados que residem nos lotes possuem fossa negra como forma de descarte para os dejetos humanos.

O sistema de tratamento consiste em gradeamentos para a remoção de resíduos sólidos, reator anaeróbio de fluxo ascendente e contínuo (UASB), seguidos de filtros biológicos e unidade de cloração. A capacidade da estação para tratamento de efluente doméstico é de até 1.000 habitantes, sendo utilizada, atualmente, para 800 habitantes. Após o tratamento, o efluente 
tratado (final) é lançado no Córrego Andes - Rio Jacaré-Guaçú, considerado como classe $2^{5}$.

A eficiência de remoção da Estação de Tratamento de Efluentes (ETE) é de $85 \%$, dentro do valor permitido para lançamento de efluentes em corpo receptor, de acordo com a Resolução CONAMA 375/2005.

O destino dos resíduos sólidos é um problema ambiental e no assentamento não é diferente, apesar da coleta ser realizada uma vez por semana na agrovila e em algumas estradas do assentamento, nos lotes onde não ocorre coleta, os assentados enterram ou queimam os resíduos.

Em relação à dimensão ambiental, uma das questões levantadas é com relação às APPs, observando se o assentado tem conhecimento de sua existência, bem como, se esta área é por ele utilizada. Na Figura 6 pode-se verificar que $38,5 \%$, o que corresponde a cinco entrevistados, responderam que utilizam as APPs.

Apesar de um número relativamente grande de assentados $(5 / 38,4 \%$ da amostra), utilizar as APPs, 61,5\% (8 assentados), não fazem uso dessas áreas e consideram que sua utilização pode acarretar prejuízos ambientais tanto para eles, quanto para o assentamento. Já os assentados que utilizam os recursos naturais das APPS, consideram que o seu uso não acarreta prejuízo ao meio ambiente ou aos outros assentados, inclusive existe a ideia de que utilizar significa, em última instância cuidar.

Entre os usos mais comuns das APPs estão a utilização da água para irrigação da lavoura e para dessedentação de animais. Observa-se na área do assentamento, um córrego sem a mata ciliar, o que segundo os moradores facilita o acesso de animais.

Com relação ao texto legal que autoriza o uso das APPs, $100 \%$ dos entrevistados, ou seja, 13 assentados desconheciam qualquer lei que permita o uso dessas áreas.

A existência de conflitos entre os assentados devido ao uso dos recursos naturais das APPs para criação de gado e para a lavoura foi apontada por $46,1 \%$ dos entrevistados (6 assentados). Por outro lado, 53,9\% dos entrevistados, que corresponde a 7 assentados, afirmam não conhecer a existência de conflitos em relação ao tema ou simplesmente, não quiseram pronunciar-se.

\footnotetext{
${ }^{5}$ O objetivo desta classificação é possibilitar a determinação dos usos preponderantes, adequação dos controles de poluição e criar instrumentos para avaliar a evolução da qualidade dos corpos d'água. De acordo com a Resolução CONAMA N. 20 de 18 de junho de 1986, a Classe 2 são águas destinadas ao abastecimento doméstico após tratamento convencional; à proteção das comunidades aquáticas; à recreação de contato primário; irrigação de hortaliças e frutíferas; à criação natural e/ou intensiva de espécies destinadas à alimentação humana, por possuírem características físico-químicas especificas.
} 
Por meio da pesquisa, foi possível também avaliar o conhecimento dos assentados sobre a existência da RL, tendo como ótica a sua demarcação, uso e outras questões descritas a seguir.

Observa-se que, a maioria dos assentados informaram que conhecem a existência das $R L$ que foi demarcada pelo Incra e localizada ao redor do assentamento e apenas 2 assentados responderam não ter conhecimento sobre o tema.

No período de 2006 a 2009 foi realizado o georreferenciamento do projeto por equipe de agrimensura, que reorganizou e redemarcou as áreas de $\mathrm{RL}$ e APPs, estabelecendo os limites necessários para preservação ambiental, conforme legislação.

A área de RL do assentamento Bela Vista (que soma aproximadamente 700 hectares distribuídos em 14 fragmentos) encontra-se em procedimento de averbação.

Por sua vez, a utilização da área de $R L$, segundo os assentados, está representada na Figura 5.

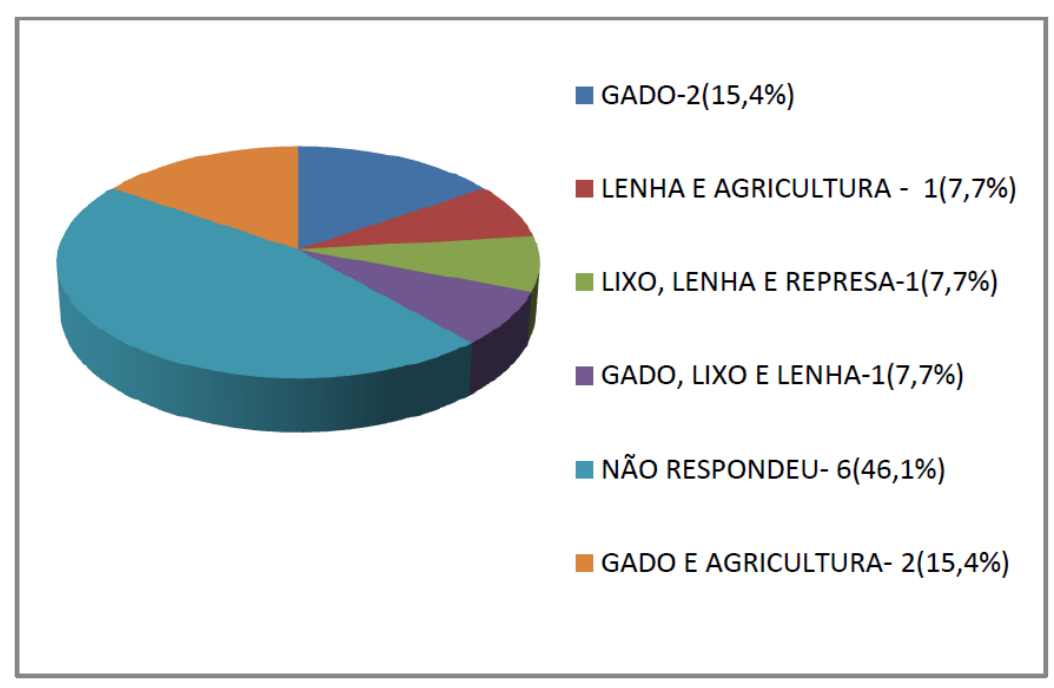

Figura 5: Uso das áreas de RL. Fonte: Silva (2011).

Observa-se que 15,4\% (2 assentados) afirmam utilizar os recursos ambientais e as áreas de RL existente no assentamento; apesar de grande parte dos entrevistados não utilizarem essas áreas, estes ainda apontaram problemas existentes e a utilização desses recursos por outros assentados. Merece destaque entre as informações obtidas a utilização da área de RL para a criação de gado, para lavoura, o corte de lenha, o depósito de resíduos, além do uso da água. 
O prejuízo acarretado pela utilização dessas áreas aos assentados é indicado por $69,2 \%$ (9 assentados), $23,1 \%$ (3 assentados) consideram que não causam prejuízo sua utilização e um entrevistado $7,7 \%$ (1 assentado) não respondeu a essa questão.

Por sua vez, para verificar o conhecimento do assentado em relação à existência da norma ambiental que o autorize a utilizar de algum modo a área de $R L$, ou sobre a existência de alguma licença expedida pelo IBAMA com a mesma finalidade, 12 dos entrevistados (92,3\%) desconhecem qualquer licença expedida e, um entrevistado 7,7\% não soube responder.

Essa falta de conhecimento sobre a legislação ambiental, faz com que as propriedades rurais familiares estejam em desacordo com a lei, tornando os assentados passíveis de multas e penalidades.

Essa falta de conhecimento da legislação pode ser atribuída pela falta de assistência técnica por parte dos órgãos de extensão rural, cooperativas e associações, que muitos assentados não têm acesso, portanto, não teriam como conhecer a legislação. Também há uma ausência do que consta em várias leis ambientais que é a Educação Ambiental. Um processo participativo de educação ambiental que envolvesse vários órgãos que tem interface com o rural seria de fundamental importância para que houvesse uma melhor compreensão das famílias rurais sobre o meio ambiente e as próprias leis ambientais (GODOY, et. al., 2009).

Tal fato pode ser confirmado quando analisada a autorização do uso da $R L$, dos quais $38,5 \%$ ( 5 assentados) dos entrevistados já terem ouvido falar em alguma lei que os autorizem a usar as áreas da $\mathrm{RL}$, não sabem dizer qual é a lei nem seu conteúdo, e 61,5\% (8 assentados) desconhecem qualquer lei que os autorizem a utilizar essas áreas.

Apesar de não terem conhecimento do conteúdo da lei que torna obrigatório deixar $20 \%$ da área como $R L, 100 \%$ (13 assentados) dos entrevistados consideram que a proteção legal e a restrição quanto ao uso não causam prejuízo a eles.

Dos conflitos que se apresentam no assentamento com relação à área de $R L$, os assentados entrevistados apontaram algumas causas como o corte de lenha, a criação de gado e a lavoura; em alguns casos de conflitos, o INCRA interveio e determinou inclusive a perda do lote.

As preocupações com o meio ambiente são evidentes nos dias atuais e necessitam de um aparato legal aliado à fiscalização, porque só a letra da lei não é possível assegurar o seu cumprimento.

A legislação brasileira no que diz respeito à questão ambiental é vasta, mas não impede de encontrar infrações ambientais em propriedades rurais, quer sejam essas infrações ligadas a APPs ou área de RL. 
Foi possível avaliar o conhecimento que o assentado possui da legislação ambiental; é possível afirmar que dentre os entrevistados os que mais se preocupam com o meio ambiente, e consideram a natureza como uma dádiva a ser conservada, são aqueles que desde criança cresceram em ambiente rural, ou seja, que mantêm um vínculo com a terra; já os oriundos da região urbana não manifestaram a mesma preocupação ou intenção de preservação ambiental.

Os dados apontam que $61,5 \%$ da amostra (8 assentados), são oriundos de áreas ou atividades não agrícolas, e 38,5\% (5 assentados), já trabalhavam com agricultura antes de serem assentados.

Em virtude do assentamento Bela Vista ter sido criado desde 1991, a situação dos assentados já está em parte estável, ou seja, possuem moradia e produzem habitualmente no seu lote, a maioria deles faz uso de rotação de culturas e utilizam habitualmente curvas de nível.

As questões ambientais levantadas são de extrema importância, haja vista que a exploração de determinadas áreas nem sempre é permitida por lei e podem causar danos irreversíveis ao meio ambiente e, por conseguinte, ocasionar a diminuição do fluxo hídrico ou até a improdutividade do solo.

Segundo as informações do coordenador técnico do INCRA que atuou no assentamento de 2004 a 2009, o INCRA realizou articulações com o Ministério Público Federal, Polícia Ambiental e Promotoria do Meio Ambiente de Araraquara, o DEPRN (a própria averbação das áreas ambientais foi uma iniciativa importante) para tentar solucionar alguns destes problemas. Também iniciou negociações com a Usina Zanin (hoje Grupo Cosan), para reduzir problemas ambientais causados pelo cultivo de cana-de-açúcar, mas com certeza há muito por fazer nesta área, ainda são ações iniciais, com poucos resultados concretos, no sentido de recuperação ambiental das áreas degradadas.

Os assentados organizam-se em associações, porém os dados levantados com relação a essas associações refletem a falta de preocupação com a problemática ambiental, sendo apenas objeto de preocupação questões relativas à produção da lavoura e comercialização da mesma.

A fiscalização ambiental existente no assentamento é proveniente do próprio INCRA, ou é feita pela Polícia Ambiental, ou quando esta recebe alguma denúncia. As informações corroboram com as obtidas no questionário técnico.

De um modo geral, os assentados possuem a percepção de que o meio ambiente precisa ser preservado para garantir a biodiversidade e a renovação do mesmo, mas essa percepção não é oriunda de legislação: ela vem da prática, da lida diária que o assentado tem com a terra, ou da tradição de práticas conservacionistas transmitidas por seus familiares. 


\section{Considerações Finais}

A legislação ambiental no país é ampla e pode ser considerada suficiente para garantir as condições de preservação do meio ambiente; porém, a letra da lei por si só não basta: são necessários instrumentos legais que garantam sua aplicabilidade, tais como a necessidade de imposição de multas em caso de desrespeito e fiscalização constante.

Cabe ressaltar a importância da integração das normas ambientais com a realidade no assentamento, que nem sempre favorece o cumprimento da norma ambiental avaliada, quer seja por desconhecimento da mesma ou pelo modo (costume) de se lidar com a terra, ou ainda a falta de uma fiscalização efetiva para o cumprimento da norma ambiental.

Dentre as preocupações ambientais dos assentados, as mais comuns são as queimadas, sejam essas acidentais ou provocadas, o destino de resíduos de forma inadequada, seja em área de reserva ou em outro local, o assoreamento dos rios e córregos e a contaminação do solo pelo uso de agrotóxicos.

Incentivos públicos por meio de programas direcionados ao produtor rural vêm ao encontro dessa proposta. Por exemplo, a Agência Nacional de Águas (ANA) desenvolveu um programa pioneiro no Brasil, denominado de "Produtor de Água". O Programa prevê que os projetos contemplem o pagamento por serviço ambiental aos produtores em função das suas ações que favoreçam os serviços ecossistêmicos e que gerem externalidades positivas à sociedade. Os produtores rurais devem adotar boas práticas, tais como práticas mecânicas, manutenção e recomposição da vegetação natural e agropecuária sustentável, que contribuam para o abatimento efetivo da erosão e da sedimentação, bem como aumento da infiltração de água na bacia hidrográfica (ANA, 2014).

Os assentados que mais apresentaram preocupação em preservar as APPs e áreas de $R L$ foram justamente aqueles que desde cedo tiveram contato com a terra, ou seja, aqueles que nasceram no campo e consideram que suas atitudes podem influenciar diretamente o ecossistema.

A proteção ambiental, para ser eficaz, necessita de legislação, fiscalização efetiva e conscientização pública, - só assim será possível caminhar para um equilíbrio ambiental em que as riquezas naturais poderão ser utilizadas com maior responsabilidade e eficiência.

Os dados apresentados na análise das dimensões estudadas fornecem dados relevantes para a literatura na área, visto que traça um perfil dos assentados, seus dilemas, conhecimento/desconhecimento da legislação ambiental e outros pontos importantes, fornecendo subsídios para a implementação de políticas públicas voltadas às suas necessidades.

A pesquisa aponta ainda, para a necessidade de uma atividade educativa de caráter ambiental, para a construção de um projeto de educação ambiental baseado nas necessidades desta comunidade. 
Talvez a solução que se apresenta para minimizar ou solucionar os problemas existentes no assentamento Bela Vista viria com a integração entre Assentados -INCRA - Universidade.

Essa parceria poderia melhorar o diálogo entre os atores e a presença da universidade, buscando identificar as necessidades imediatas e de médio prazo dos assentados, observando-se, no entanto, que uma ação técnico-educativa a ser desenvolvida no assentamento deve levar em conta a história do grupo, sua trajetória de vida.

É importante destacar que, qualquer proposta concreta a ser implementada deve ser construída a partir de um processo participativo dos assentados.

Ainda há muito que se fazer no assentamento Bela Vista do Chibarro em questões ambientais, mesmo porque muitos assentados desconhecem a lei. As limitações ao uso das áreas de RL e APP muitas vezes são impostas aos assentados em forma de multa, sem que fosse a eles explicado o motivo pelo qual se devam preservar essas áreas.

\section{Referências}

ALENCASTRO, M.A.C. Indicadores de cumprimento da norma ambiental na conservação e preservação da vegetação em áreas de assentamento de reforma agrária. Fortaleza, 2007. Dissertação (Mestrado em Desenvolvimento e Meio Ambiente) - Universidade Federal do Ceará.

ANA, Agência Nacional de Águas. Programa Produtor de Águas. Disponível em: http://produtordeagua.ana.gov.br/Resultado.aspx. Acessado em 11 de abril de 2015.

FERREIRA NETO, J.A.; DOULA, S.M. Assentamentos rurais e meio ambiente no Brasil: atores sociais, processos produtivos e legislação. Viçosa, Universidade Federal de Viçosa, 2006.

GODOY, C.M.T.; HILLING, C.; PÉREZ, F.I.C.; SILVEIRA, G.H. A Legislação ambiental e os dilemas da agricultura familiar. Revista Brasileira de Agroecologia, Rio Grande do Sul, v. 4, n.2, p. 913-916, nov. 2009.

RODRIGUES, L.L.M.; SILVA, A.R.O.; MOREIRA, E. R. F. Da luta por terra à vida na terra: um exemplo do embate entre capital e trabalho no campo. In: JORNADA DO TRABALHO, IX, 2008, Catalão. Anais..., Catalão: UFG, 2008.

SILVA, A. M. R. C. Análise ambiental do Assentamento Bela Vista do Chibarro (Araraquara-SP): legislação incidente, uso e ocupação do solo e percepção ambiental. Araraquara, 2011. Dissertação (Mestrado em Desenvolvimento Regional e Meio Ambiente) - Centro Universitário de Araraquara.

TRINDADE, E.S.; SCAEFER, C.E.G.R; MUNIZ, J.N. Avaliação ambiental em áreas de assentamento de reforma agrária: o caso do PA Campo Novo, Jequitinhonha, MG, In: FERREIRA NETO, J.A.; DOULA, S.M. (Org.). Assentamentos rurais e meio ambiente no Brasil: atores sociais, processos produtivos e legislação. Viçosa: Universidade Federal de Viçosa, 2006, v.1, p. 19-62. 